Das hochinteressante Tier macht beim Sammeln den Eindruck eines Anillus und zeigt die Tastbewegungen der Fühler und die seitlichen Drehbewegungen des Vorderkörpers wie manche Blindcarabiden.

\title{
Eine Podagrica (Col., Chrysomel.) mit einem dritten, zwischen Clipeus und Labrum eingelenkten Fühler.
}

Von Franz Heikertinger, Wien.

(Mit 1 Figur.)

Seit es bekannt ist, daß die Präimaginalstadien der Käfer die Fähigkeit besitzen, verloren gegangene Körperteile durch Regeneration

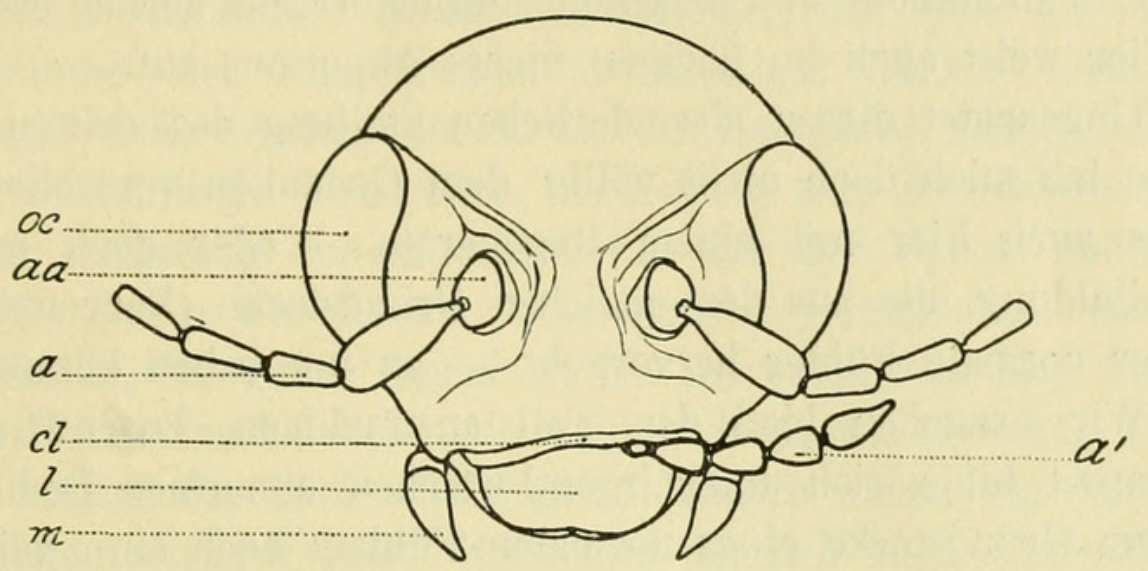

Fig. 1.

Podagrica maliae.

Kopf mit monströsem dritten Fühler; $o c$ Auge; $a a$ Pfannenglied der Fühler; $a$ Fühler; $c l$ Kopfschild; $l$ Oberlippe; $m$ Unterkiefertaster; $a^{\prime}$ dritter Fühler.

zu ersetzen, seit wir wissen, daß aus einer an einer Extremität entstandenen Wunde der von der Wunde peripher gelegene Teil der Extremität ein zweites-, drittes- oder öfteresmal hervorwachsen kann, daß man im stande ist, Vervielfältigungen von Fühlern, Beinen usw. experimentell hervorzurufen - seit dieser Zeit haben Mißbildungen dieser Art wesentlich an Interesse eingebülot. Die experimentelle Biologie hat sie als Regenerate gekennzeichnet, die gewissermaßen auf einem Irrtum der Natur bei ihrem Streben, Verlorenes zu ersetzen, beruhen. Die Natur ersetzte, durch die Wunde irregeführt, Unverlorenes; sie verdoppelte oder vervielfachte es hiedurch und erreichte damit zuweilen das Gegenteil von dem, was durch die Regeneration hätte erreicht werden sollen - das Regenerat war funktionsunfähig.

Wien. Entom. Zeitung, XXXIV. Jhg., Heft VIII-X, Festschr. f. Reitter (22. Okt. 1915). 
Die Monstrosität, die ich im folgenden charakterisieren möchte, hat mit solchen einfachen Fällen von Regeneration nichts zu tun.

Es handelt sich um einen Käfer (ein Exemplar der Halticine Podagrica malvae semirufa), der neben zwei völlig normal entwickelten, elfgliedrigen Fühlern einen dritten Fühler an einer Stelle des Kopfes aufweist, der sonst keinerlei Extremitäten zu tragen pflegt.

Dieser dritte Fühler, der aus vier regelmäßigen, kurzen, aber wohlgebauten Gliedern und einem kleinen Wurzelgliede besteht, mittels dessen er beweglich eingelenkt ist, erreicht eine Länge, die ungefähr der Summe der Längen der drei ersten Glieder des Normalfühlers entspricht; er entspringt unter dem Vorderrande des Clipeus, zwischen Clipeus und Labrum, etwas links (vom Käferkörper aus betrachtet) von der Längsmitte des Kopfes; Clipeus und Labrum erscheinen durch ihn ein wenig auseinandergezwängt und hiedurch leicht asymmetrisch. Mandibeln und Maxillen sind beiderseits normal entwickelt; das Tier weist auch im übrigen nichts Abnormes auf.

Ungeachtet dieser absonderlichen Stellung des dritten Fühlers möchte ich mich doch nicht völlig dem Gedanken verschließen, daß wir es auch hier mit einem Regenerate - oder doch mit einer Doppelbildung, die aus dem gleichen Grundstocke (Nervenzentrum?) wie der normale Fühler hervorgeht - zu tun haben können.

Wir brauchen bloß den Fall anzunehmen, innerhalb der Kopfkapsel bilde sich unter irgend welchen abnormen Bedingungen aus dem Grundstocke eines normalen Fühlers noch ein zweiter, abnormer Fühler. Dieser zweite Fühler, dem der Weg durch dås Fühlerpfannenloch durch den normalen Fühler versperrt ist, wächst längS der Innenwand der Vorderstirn weiter und tritt dort, wo diese Stirnwand endet, zu Tage. Das wäre die Stelle zwischen dem Vorderrand des Kopfschildes (Anteclipeus) und der Oberlippe, dem Labrum, das als freie Platte in das Vorderkopfloch eingeschoben und mit zwei langen Seitenfortsätzen im Kopfe befestigt ist ${ }^{1}$ ) - eben jene Stelle, an der der hier beschriebene Fühler tatsächlich zu Tage tritt.

Durch die Vermutung dieser Möglichkeit - es soll nicht mehr sein als eine solche - wäre auch diesem Falle das prinzipiell Absonderliche, das ihm auf den ersten Blick anhaftet, genommen.

Das monströse Tier befindet sich in meiner Sammlung; es stammt von Larnaka auf Cypern.

1) Vgl. meine Abbildungen in: Verh. Zool.-bot. Ges. Wien, 63. Bd, S. 107; 1913. - Münchn. Koleopt. Zeitschr., IV, S. 278; 1915. - Zeitschr. f. angew. Entomologie, II, S. $14 ; 1915$. 


\section{$2 \mathrm{BHL}$ Biodiversity Heritage Library}

Heikertinger, Franz. 1915. "Eine Podagrica (Col., Chrysomel.) mit einem dritten, zwischen Clipeus und Labrum eingelenkten Fühler." Wiener entomologische Zeitung 34, 335-336. https://doi.org/10.5962/bhl.part.10624.

View This Item Online: https://www.biodiversitylibrary.org/item/43833

DOI: https://doi.org/10.5962/bhl.part.10624

Permalink: https://www.biodiversitylibrary.org/partpdf/10624

\section{Holding Institution}

Smithsonian Libraries

\section{Sponsored by}

Smithsonian

\section{Copyright \& Reuse}

Copyright Status: NOT_IN_COPYRIGHT

This document was created from content at the Biodiversity Heritage Library, the world's largest open access digital library for biodiversity literature and archives. Visit BHL at https://www.biodiversitylibrary.org. 